\title{
ROLE OF HEART RATE REDUCTION WITH IVABRADINE IN LEFT VENTRICULAR FAILURE
}

\author{
Safia Batool, Jamal Waris, Muhammad Usman Sajid, Shazia Nisar*, Imran Khan**, Hina Mushtaq*** \\ Combined Military Hospital Jhelum/National University of Medical Sciences (NUMS) Pakistan, *Pak Emirates Military Hospital/National \\ University of Medical Sciences (NUMS) Rawalpindi Pakistan, ${ }^{* *}$ Combined Military Hospital Peshawar/National University of Medical \\ Sciences (NUMS) Pakistan, ${ }^{* * *}$ Rehman Medical Institute, Peshawar Pakistan
}

\begin{abstract}
Objective: To compare mean heart rate reduction in Ivabradine and placebo group in left ventricular failure patients.

Study Design: Quasi experimental study.

Place and Duration of Study: Study was conducted at Combined Military Hospital, Kharian, from Jul 2018 to Dec 2018.

Methodology: Sixty four patients participated in the study. They were randomly divided into two groups of 32 each. One group was given Tab Ivabradine (10 mg twice a day) while second group received a placebo for a period of 4 weeks. After 4 weeks each patient was evaluated and heart rate, systolic and diastolic blood pressure were recorded. Mann-whitney $U$ test selected to compare heart rate and ages of both groups t- test used to compare systolic and diastolic blood pressure among both groups. Chi-square test used to determine the association of heart rate between two groups. A $p$-value $\leq 0.05$ was considered significant.

Results: Median (IQR) heart rate was significantly lower in Ivabradine group 58.3 (4) as compared to placebo 64.1(1) $(p<0.01)$. Systolic blood pressure $(132.8 \pm 3.6)$ was significantly lower in ivabradine group as compared to placebo group $(137.1 \pm 4.5)(p<0.01)$. Difference in diastolic blood pressure was insignificant in both groups $(p=$ $0.55)$. There was a significant association between heart rate of 55-60 beats per minute and ivabradine use $(p<0.01)$.

Conclusion: Ivabradine is safe and efficative drug in reducing heart rate and systolic blood pressure for patients suffering from left ventricular failure. Early detection and management of left ventricular failure with ivabradine use leads to better prognosis of the disease.
\end{abstract}

Keywords: Heart rate, Ivabradine, Left ventricular failure.

This is an Open Access article distributed under the terms of the Creative Commons Attribution License (http://creativecommons.org/licenses/by/4.0), which permits unrestricted use, distribution, and reproduction in any medium, provided the original work is properly cited.

\section{INTRODUCTION}

Heart failure is worldwide public health issue with an estimated prevalence of 23 million worldwide ${ }^{1}$. Prevalence of heart failure in United States is 5.8 million$^{2}$. American Heart Association defined heart failure as complex clinical syndrome as a result of functional and structural cardiac diseases leading towards failures of ventricle ability (filling and ejecting blood) ${ }^{3}$.

Left ventricular failure refers to left ventricle dysfunction leading towards insufficient blood delivery to vital body organs ${ }^{4}$. Left ventricular heart failure is classified into i) heart failure (HF)

Correspondence: Dr Safia Batool, Village Ghura Jattan Post Office Nathwala, The Dina Distt, Jhelum Pakistan

Received: 30 Mar 2020; revised received: 22 Jun 2020; accepted: 16 Sep 2020 with preserved ejection fraction (over $50 \%$ ), ii) $\mathrm{HF}$ with reduced ejection fraction $(<40 \%)$ and iii) HF with mid range ejection fraction (41-49\%) ${ }^{5}$. Most common etiologies for left ventricular failure are ischemic heart diseas and hypertension. Prevalence of ischemis heart disease in Pakistan is 26.9\% leading towards left ventricular failure ${ }^{6}$. Left ventricular hypertrophy also leads to left ventricular failure. Smoking, diabetes mellitus, obesity, life style and male gender are important risk factors for left ventricular failure ${ }^{7}$.

Pathophysiology of left ventricular failure includes multiple mechanisms. Poorly controlled hypertension is responsible for increased cardiac workload and after load resulting towards hypertrophy. In initial stage, hypertrophy act as compensatory mechanism and help in maintaining 
heart output. However, Long term hypertrophyinhibits myocardium relaxation leading towards decreased left ventricular output and impaired cardiac filling 8 . Moreover, coronary arterial disease results in direct ischemic damage, arrhythmias leads to remodeling, cardiomyopathies are responsible for multiple mechanisms causing cardiac dysfunction and left ventricular failure ${ }^{9}$.

Ivabradine is a selective If channel inhibiting drug. Ivabradine helps in heart rate reduction by specifically and selectively inhibiting If channels ${ }^{10}$. Literature reported that ivabradine decrease heart rate witout any effect on myocardial relaxation and contractility, blood pressure and ventricular repolarization/myocardial conduction $^{11 .}$

Fox et al reported that mean heart rate in ivabradine group was $60.7 \pm 9.0$ beats per minute while in placebo group was $70.6 \pm 10.1$ beats per minute. Incidence of bradycardia was high in ivbradine group (18\%) as compared to placebo $(2.3 \%) p<0.001^{12}$. Pascual et al reported that ivabradine is well tolerated for heart rate reduction. Ivabradine represents as an attractive option for excessive catecholamine related tachycardia ${ }^{13}$. Limited data is available in Pakistan on role of ivabradine in heart rate reduction. Present study aims to compare mean heart rate reduction in Ivabradine and placebo group in left ventricular failure patients.

\section{METHODOLOGY}

This quasi experimental study was conducted at, Combined Military Hospital, Kharian. Study duration was 6 months (Jul 2018 to Dec 2018). A sample size of 64 patients calculated with $\mu 1=70.6, \mu 2=60.7, S D=10.1,95 \%$ confidence interval, power of study $84 \%$ using WHO calculator ${ }^{12}$. Non probability consecutive sampling used for patient's selection. Study approval was obtained from ethical review committee. Consent forms were taken from all participants. Patients with age $>18$ years, both gender, patients with heart rate (resting) $70 \mathrm{bpm}$ on two consecutive electrocardiographic readings, patients diagnosed with left ventricular failure were included in study. Patients with unstable cardiovascular condition, pulmonary diseases, poor liver function, severe psychological issues, pregnant and breast feeding mothers were excluded from study. History of previous ischemic event (myocardial infarction), revascularization and diabetes mellitus was recorded. Body mass index (BMI) was also calculated. Patients were randomly divided into ivabradine and placebo groups with 32 patients in each group using computer generated random numbers table. Ivabradine group was given Tab Ivabradine $10 \mathrm{mg}$ twice daily while placebo group patients received placebo twice daily for 4 weeks. After 4 weeks of drug use by each group, patients were evaluated for heart rate, systolic and diastolic blood pressure changes. Data was analyzed using SPSS version 16. Descriptive statistics and normality tests were computed for age, heart rate, systolic and diastolic BP while frequency and percentages were calculated for categorical data. Mann whitney U-test was selected to compare the heart rate as well as ages of both groups and $t$ test was used to compare the systolic and diastolic BP of both groups. To compare the association of heart beat between the two groups, chi-square test was computed. A $p$-value $\leq 0.05$ was considered statistically significant.

\section{RESULTS}

A total of 64 patients participated in the study. Median (IQR) age of the patients was 47.5 (9.5) years. There were $40(62.5 \%)$ males and 24 (37.5\%) females. Eight (12.5\%) patients belonged to age group $18-40$ years while 56 (87.5\%) patients were from age group $>40$ years. Twenty Six $(40.6 \%)$ patients were grouped with BMI $\leq 28$ $\mathrm{kg} / \mathrm{m}^{2}$ while $38(59.4 \%)$ were grouped with BMI $>28 \mathrm{~kg} / \mathrm{m}^{2}$. Previous revascularization was found in $34(53.1 \%)$ patients while $30(46.9 \%)$ did not show previous revascularization. History of myocardial infarction was reported in 34 (53.1\%) while $30(46.9 \%)$ did not have a history of myocardial infarction. Forty six $(71.9 \%)$ patients were diabetic and remaining 18 (28.1\%) patients were non diabetic. 
Median (IQR) heart rate was significantly lower in ivabradine groupas compared to placebo group (table-I). A statistically significant fall in systolic BP was detected in ivabradine group (table-I). There was no significant difference in diastolic BP among both groups (table-I).

There was a significant association between heart beat of 55-60 bpm and ivabradine use with majority of patients having a heart beat of 55-60 is also associated with reducing ischemia and reduce symptoms among stable angina pectoris patients ${ }^{16}$.

In the current study, total 64 patients participated. Median (IQR) heart rate was significantly lower in ivabradine group 58.3(4) as compared to placebo 64.1(1) $(p<0.01)$. Lechat et al described that a significant heart rate reduction was observed with ivabradine without hemodynamic alte-

Table-I: Comparison of Heart rate, systolic BP and diastolic BP in Ivabradine and placebo group (n=64).

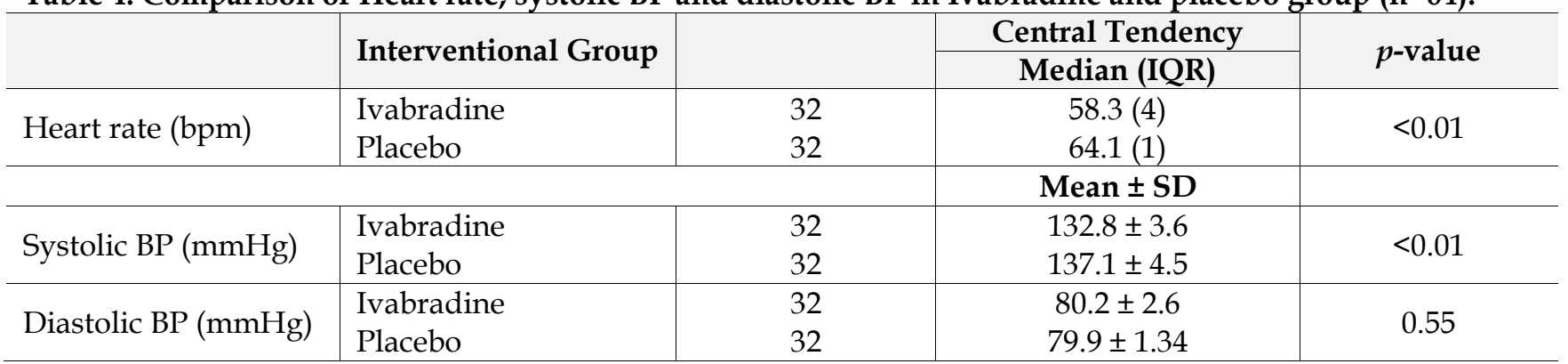

Table-II: Comparison of Heart beat with ivabradine and placebo groups $(n=64)$.

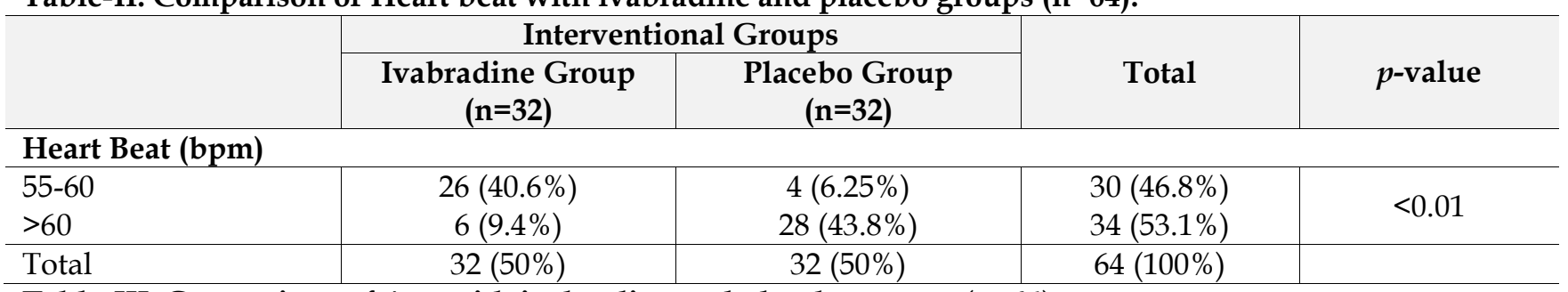

Table-III: Comparison of Age with ivabradine and placebo groups $(n=64)$.

\begin{tabular}{|c|c|c|c|c|}
\hline & \multicolumn{2}{|c|}{ Interventional Groups } & \multirow[b]{2}{*}{ Total } & \multirow[b]{2}{*}{$p$-value } \\
\hline & $\begin{array}{l}\text { Ivabradine Group } \\
\qquad(\mathrm{n}=32)\end{array}$ & $\begin{array}{l}\text { Placebo Group } \\
\quad(n=32)\end{array}$ & & \\
\hline \multicolumn{5}{|c|}{ Age Categories } \\
\hline $\begin{array}{l}18-40 \text { yrs } \\
>40 \text { yrs }\end{array}$ & $\begin{array}{c}6(9.4 \%) \\
26(40.6 \%)\end{array}$ & $\begin{array}{c}2(3.1 \%) \\
30(46.8 \%)\end{array}$ & $\begin{array}{c}8(12.5 \%) \\
56(87.5 \%)\end{array}$ & 0.13 \\
\hline Total & $32(50 \%)$ & $32(50 \%)$ & $64(100 \%)$ & \\
\hline
\end{tabular}

bpm in Ivabradine group (table-II). Both groups were age matched as there was no statistical difference in the median ages of two groups $(p=0.13)$ as shown in table-III. No adverse effects were reported with Ivabradine in our study.

\section{DISCUSSION}

An increased heart rate is a significant marker of cardiovascular diseases risk in general population ${ }^{14}$. Ivabradine is associated with inhibition of If in sinoatrial node leading towards heart rate reduction without placing an effect on left ventricular systolic function ${ }^{15}$. Ivabradine rations $(100 \mathrm{bpm} \pm 25$ baseline, $82 \mathrm{bpm} \pm 12, p=$ $0.000)^{17}$. Flannery et al described that ivabradine is a well tolerated drig in left ventricular dysfunction patients ${ }^{18}$. Another similar study described that placebo had significantly high heart rate as compared to ivabradine (122 $\pm 17.2 \mathrm{SD} \& 88.4 \pm$ $12 \mathrm{SD}$ respectively, $p<0.001)^{19}$.

In the current study, most of the patients in ivabradine group had heart beat $55-60 \mathrm{bpm}$ as compared to placebo $(40.6 \%$ \& $6.3 \%$ respectively, $p<0.01)$. McAlister et al described that ivabradine is associated with heart rate reduction without 
effecting left filling pressure in left ventricular failure patients ${ }^{20}$. DiFrancesco et al described that $55 \%$ patients treated with ivabradine had $\leq 75 \mathrm{bpm}$ as compared to placebo $(>75 \mathrm{bpm}) p<0.01^{21}$.

In the current study, mean systolic blood pressure was significantly lower in $132.8 \pm 3.6 \mathrm{SD}$ as compared to placebo group $137.1 \pm 4.5 \mathrm{SD}(p=$ 0.03 ). Deedwania et al described that ivabradine had significant contribution in lowering systolic pressure as compared to matching placebo ( $p$ $<0.01)^{22}$. Another similar study described that ivabradine is associated with systolic blood pressure reduction without affecting diastolic pressure in acute heart failure ${ }^{23}$.

In the current study, there were no adverse effects observed with ivabradine in our study. However, Tardil et al described that ivabradine patients showed symptomatic bradycardia and visual side effects as adverse events ${ }^{24}$.

\section{LIMITATION OF STUDY}

Small sample size and conduction of study at single center limits generalisability of study.

\section{CONCLUSION}

Ivabradine is safe and highly effective drug in reducing heart rate among left ventricular failure patients. Early detection and management of left ventricular failure with ivabradine leads to better prognosis of the disease.

\section{CONFLICT OF INTEREST}

This study has no conflict of interest to be declared by any author.

\section{REFERENCES}

1. Ponikowski P, Voors A, Anker S. ESC Guidelines for the diagnosis and treatment of acute and chronic heart failure. Eur Heart J 2016; 37(2): 2129-200.

2. Mosterd A, Hoes AW. Clinical epidemiology of heart failure. Heart 2007; 93(2): 1137-46.

3. Drug and Therapeutics Bulletins. Ivabradine for chronic heart failure? DTB 2012; 50(3): 117-20.

4. Kenworthy W, Guha K, Sharma R. The patient with left ventricular systolic dysfunction now and in the future. Br J Hosp Med (Lond) 2016; 77(2): 516-522.

5. Mozzafarian D, Benjamin EJ, Go AS, et al. Heart disease and stroke statistics 2016 update: a report from the American Heart
Association. Circulation 2016; 133(3): e38-60.

6. Jafar TH, Jafary FH, Jessani S, Chaturvedi N. Heart disease epidemic in Pakistan: women and men at equal risk. Am Heart J 2005; 150(2): 221-26.

7. Kannel WB, Kannel C, Paffenbarger RS. Heart rate and cardiovascular mortality: the Framingham Study. Am Heart J 1987; 113(4): 1489-94.

8. Palatini $\mathrm{P}$, Julius S. Association of tachycardia with morbidity and mortality: pathophysiological considerations. J Hum Hyperten 1997; 11(2): 19-27.

9. Cook S, Togni M, Schaub MC. High heart rate: a cardiovascular risk factor? Eur Heart J 2006; 27(3): 2387-93.

10. Fox K, Borer JS, Camm AJ. Resting heart rate in cardiovascular disease. J Am Coll Cardiol 2017; 50(2): 823-30.

11. Reil JC, Bohm M. The role of heart rate in the development of cardiovascular disease. Clin Res Cardiol 2017; 96(3): 585-92.

12. Fox K, Ford I, Steg PG, Tardif JC, Tendera M, Ferrari R. Signify Investigators. Ivabradine in stable coronary artery disease without clinical heart failure. N Engl J Med 2014; 371(12): 1091-99.

13. Izco MP, Carracedo RR, Navarro HI, Ruiz OÁ, Navarro CB, Berrocal CI, et al. Ivabradine in acute heart failure: Effects on heart rate and hemodynamic parameters in a randomized and controlled swine trial. Cardiol J 2018; 29(2): 123-26.

14. Custodis F, Reil JC, Laufs U. Heart rate: a global target for cardiovascular disease and therapy along the cardiovascular continuum. J Cardiol 2013; 62(2): 183-87.

15. Bui AL, Grau-Sepulveda MV, Hernandez AF. Admission heart rate and in-hospital outcomes in patients hospitalized for heart failure in sinus rhythm and in atrial fibrillation. Am Heart J 2013; 165(1): 567-74.

16. Laskey WK, Alomari I, Cox M. AHA get with the guidelines ${ }^{\circledR}-$ heart failure program. Heart rate at hospital discharge in patients with heart failure is associated with mortality and rehospitalization. J Am Heart Assoc 2015; 22(3): e001626.

17. Lechat P, Hulot JS, Escolano S. Heart rate and cardiac rhythm relationships with bisoprolol benefit in chronic heart failure in CIBIS II Trial. Circulation 2001; 103(3): 1428-33.

18. Flannery G, Gehrig-Mills R, Billah B, Krum H. Analysis of randomized controlled trials on the effect of magnitude of heart rate reduction on clinical outcomes in patients with systolic chronic heart failure receiving beta-blockers. Am J Cardiol 2008; 101(3): 865-69.

19. McAlister FA, Wiebe N, Ezekowitz JA. Meta-analysis: betablocker dose, heart rate reduction, and death in patients with heart failure. Ann Intern Med 2009; 150(11): 784-94.

20. Vilaine JP. The discovery of the selective If current inhibitor ivabradine. A new therapeutic approach to ischemic heart disease. Pharmacol Res 2006; 53(2): 424-34.

21. DiFrancesco D, Camm JA. Heart rate lowering by specific and selective If current inhibition with ivabradine: a new therapeutic perspective in cardiovascular disease. Drugs 2004;64(3): 1757-65.

22. Deedwania P. Selective and specific inhibition of If with ivabradine for the treatment of coronary artery disease or heart failure. Drugs 2013; 73(2): 1569-86.

23. Du XJ, Feng X, Gao XM. If channel inhibitor ivabradine lowers heart rate in mice with enhanced sympathoadrenergic activities. Br J Pharmacol 2004; 142(3): 107-12.

24. Tardif JC, Ford I, Tendera M. Efficacy of ivabradine, a new selective I(f) inhibitor, compared with atenolol in patients with chronic stable angina. Eur Heart J 2005; 26(1): 2529-36. 